\title{
DIZZINESS DAN VERTIGO DENGAN KETERKAITAN SISTEM VERTEBROBASILER
}

\author{
Ida Bagus Kusuma Putra, Felix Adrian \\ Departemen Neurologi, FK Universitas Udayana/RSUPSanglah Denpasar, Bali, Indonesia
}

Diterima 22 Februari 2019

Disetujui 23 Februari 2019

Publikasi 28 Maret 2019

Korespondensi: felixad1985@gmail.com
Cara merujuk artikel ini: Kusuma Putra (et al). 2019.

Dizzines dan vertigo dengan keterkaitan system vertebrobasiler. Callosum Neurology Journal 2(1): 18-

24.

DOI: $10.29342 /$ cnj.v2i1.56

\section{ABSTRAK}

Empat juta lebih pasien datang dengan keluhan dizziness maupun vertigo. $5 \%$ pasien yang datang dengan keluhan dizziness dan vertigo ternyata memiliki penyakit stroke. 90\% Transient ischemic attack (TIA) pada sirkulasi posterior memilki keluhan vertigo yang biasanya dihiraukan oleh petugas medis. HINTS PLUS (head impulse, tipe nistagmus, skew deviation) ditambah keluhan hilang nya pendengaran yang diperiksa de ngan gesekan tangan, dikatakan bisa menyingkirkan kemungkinan dari stroke lebih akurat bahkan dari MRI. 4 sindrom pada pasien dengan keluhan intermiten atau kontinu dizziness, dapat dibagi menjadi trigge red episodic vestibular syndrome (t-EVS), spontaneous EVS (s-EVS), traumatik/toksik acute vestibular syndrome (tAVS), spontaneous AVS (s-AVS).

Kata Kunci: vertigo, pusing, HINTS, vertrobrobasiler

\begin{abstract}
More than 4 million patients present with dizziness or vertigo. $5 \%$ of patients who come with complaints of dizziness and vertigo actually have a stroke. 90\% Transient ischemic attack (TIA) in the posterior circulation has complaints of vertigo which is usually ignored by medical personnel. HINTS PLUS (head impulse, type of nystagmus, skew deviation) plus complaints of hearing loss examined by hand friction, is said to eliminate the possibility of
\end{abstract}

more accurate stroke even from MRI. 4 syndrome in patients with intermittent complaints or continuous dizziness, can be divided into triggered episodic vestibular syndrome (t-EVS), spontaneous EVS (s-EVS), traumatic / toxic ac ute vestibular syndrome (t-AVS), spontaneous AVS (sAVS).

Keywords: vertigo, dizziness, HINTS, vertebrobasilar 


\section{Latar Belakang}

Keluhan gangguan keseimbangan dan vertigo merupakan keluhan umum yang membuat pasien datang untuk berobat. Sekitar 4.4 juta pasien datang dengan keluhan dizziness maupun vertigo. Sekitar 5 $\%$ pasien yang datang dengan keluhan gangguan keseimbangan dan vertigo disebabkan oleh stroke. Salah diagnosis pada pasien dengann stroke dengan keluhan gangguan keseimbangan terjadi sekitar $10 \%$, terutama pada usia muda ( $<50$ tahun) dan perempuan. Dari sebuah register berbasis populasi di Amerika Serikat pasien datang dengan keluhan gangguan keseimbangan memiliki resiko 50 kali lipat masuk ke rumah sakit dengan diagnosa stroke dalam 7 hari setelah dipulangkan dari IGD. 90\% Transient Ischemic attack (TIA) pada sirkulasi posterior memiliki keluhan vertigo yang biasanya dihiraukan oleh petugas medis.

CT scan memiliki sensitivitas yang rendah (7-16\%) dalam menegakan diagnosa stroke iskemik akut, khususnya pada fosa posterior. MRI dengan diffusion-weighted imaging (DWI) gagal mendiagnosa stroke pada $15-20 \%$ pasien dengan akut infark fosa posterior dengan awitan kurang dari 48 jam setelah awitan. Walaupun dari data tersebut yang terlewat dengan MRI-DWI adalah stroke yang sangat kecil (diameter $<1 \mathrm{~cm}$ ), tetapi kecil bukan berarti tidak berbahaya, karena $50 \%$ dari pasien tersebut mempunyai stenosis arteri besar atau diseksi,yang akan meningkatkan resiko stroke berulang.

Sebuah studi mengatakan bahwa stroke serebelar yang telat di diagnosa akan mempunyai angkat morbiditas dan mortalitas yang tinggi. Data menunjukkan sekitar 15000 sampai 25000 kasus mengalami suatu morbiditas yang disebabkan kareana misdiagnosa pada saat penerimaan pasien diawal. Hal ini menunjukkan sampai saat ini cara kita menegakan diagnosa masih belum optimal. ${ }^{1}$

\section{Definisi}

Keseimbangan adalah kemampuan untuk mempertahankan orientasi tubuh dengan lingkuangan sekitarnya. Keseimbangan pada manusia diatur oleh input yang bersifat kontinu dari sistem vestibular, propioseptif dan visual. Impuls dari ketiga sistem ini akan mengalami proses integrasi dan modulasi di batang otak, serebelum dan serebral. Sistem arteri vertebrobasiler memberikan perfusi menuju medula oblongata, serebelum, pons, mesensefalon, talamus dan korteks oksipital. Oklusi pada sistem pembuluh darah besar didalam sistem ini biasanya akan berakibat pada disabilitas dan kematian. Gangguan pada sistem yang berperan pada sistem keseimbangan ini akan menimbulkan gangguan keseimbangan secara definisi, gangguan keseimbangan / dizzeness merupakan suatu gangguan sensasi atau kerusakan orientasi spasial tanpa distorsi sensasi gangguan gerak dan vertigo sebagai sensasi gerak ketika tidak ada sensasi gerak yang muncul. ${ }^{1-3}$

\section{Timing, Triggers dan Targeted Examination}

Sebuah akronim berbahasa inggris TiTraTE yang merupakan singkatan dari timing, triggers dan targeted examination. Timing (waktu) melihat aspek dari onset, durasi dan evolusi dari gangguan keseimbangan. Triggers (faktor pencetus) fokus pada aksi, gerakan atau situasi yang memprovokasi dari keluhan gangguan keseimbangan pada pasien dengan gejala yang intermitent. Pada kasus akut, berdasarkan waktu dan faktor pencetus memunculkan 4 kemungkinan sindrom pada pasien yang datang ke ruang emergensi dengan keluhan intermiten atau kontinu dizziness, yaitu triggered episodi vestibular syndrome (t-EVS), spontaneous EVS (s-EVS), traumatic/ toxic acute vestibular syndrome (t-AVS), spontaneous AVS (s-AVS). Kebanyakan pasien TIA datang dengan keluhan sEVS dan kebanyakan pasien dengan stroke dan perdarahan datang dengan s-AVS (dengan beberapa pengecualian). Pada tabel 1 menggambarkan akibat dizziness atau vertigo pada kasus vaskular sedangkan pada gambar 1 dan gambar 2 menggambarkan pembagian keluhan dizziness kedalam 4 kategori.

\section{Episodic Vestibular Syndrome}

Secara defisini dikatakan sebagai sebuah sindrom klinis dengan vertigo transient, dizziness dan ketidak seimbangan yang bertahan dari detik sampai beberapa jam, dan terkadang sampai beberapa hari, dan yang terkadang disertai dengan gejala gangguan sistem vestibular (nausea, nistagmus, dan jatuh mendadak). ${ }^{1}$

\section{Triggered Episodic Vestibular Syndrome}

Pada triggered episodik vestibular syndrome, keluhan biasanya berlangsung dalam hitungan detik sampai menit. Dengan faktor pencetus paling sering disebabkan oleh pergerakan kepala atau perubahan posisi tubuh (berdiri dari posisi duduk maupun terlentang). Klinisi harus bisa membedakan apakah ini merupakan suatu yang dipicu atau meruapakan suatu eksaserbasi. Karena suatu pergerakan kepala akan mengeksersebasi suatu keluhan pusing yang disebabkan oleh masalah vestibular, baik itu merukan suatu yang benign maupun suatu yang berbahaya, sentral maupun perifer, akut maupun kronik. 
Pada ruang emergensi, keluhan benign paroxysmal positional vertigo (BPPV) merupakan keluhan ke 2 terbanyak setelah hipotensi ortostatik pada kasus t-EVS. Diagnosis BPPV di konfirmasi dengan tes

reposisi kanalis yang spesifik dan juga dengan mengevaluasi nistagmus yang sesuai dengan kanalis yang terkait. Posterior kanal BPPV merupakan yang paling sering. Posterior BPPV biasanya menghasilkan transient, kresendo-dekresendo upbeat torsional nistagmus yang bertahan kurang dari 1 menit. BPPV pada kanalis horizontal merupakan kedua yang terbanyak. Gejala berupa transient horizontal nistagmus yang berlangsung kurang dari 90 detik. Pasien dengan atipikal nistagmus berupa persistent positional downbeat atau horizontal nistagmus, tidak ada latensi, biasanya disebut dengan sentral paroksisimal positional vertigo. Sentral paroksisimal vertigo biasanya disebabkan oleh sebab sentral yang benign, biasanya disebabkan oleh karena intoksikasi alkohol atau vestibular migren, tetapi bisa juga disebabkan oleh lesi struktural pada posterior fossa.

Secara keseluruhan t-EVS sangat jarang disebabkan oleh karena penyakit serebrovaskular, tetapi ada 2 sebab vaskular yang harus dipikirkan yaitu stroke yang kecil atau perdarahan dekat ventrikel 4 yang sering kali menyebabkan sentral paroksisimal vertigo. Sebab lain yang juga cukup jarang adalah rotational vertebral artery syndrome, yang disebabkan rotasi leher yang hebat ke arah lateral akan mengakibatkan oklusi mekanik pada satu atau kedua vertebral arteri dimana akan menyebabkan keluhan vertigo dan nistagmus ketika posisi kepala menoleh ke arah yang terganggu. Keluhan ini bahkan akan muncul pada saat pasien berdiri tegak, sehingga tidak sulit membedakan dengan sentral paroksisimal positional vertigo. ${ }^{1}$

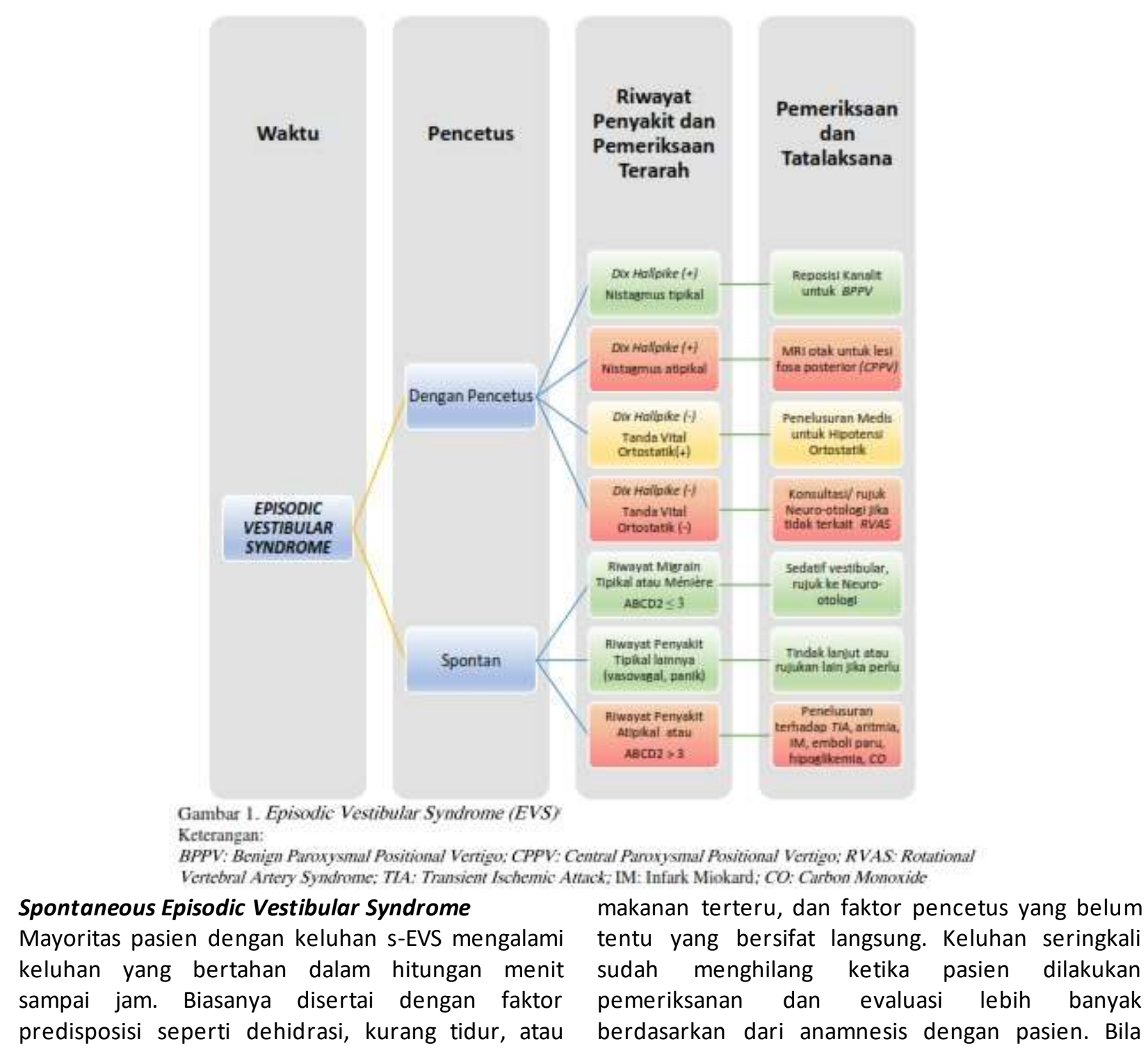

20 | Callosum Neurology Journal - Jurnal Berkala Neurologi Bali 
gejala masih bertahan pada saat dilakuakan pemeriksaan, pemeriksaan mata seperti pada s-AVS bisa untuk membedakan apakah suatu proses sentral atau perifer. ${ }^{1}$

Penyakit meniere biasanya contoh pada kasus s-EVS, walaupun yang paling sering terjadi adalah vestibular migren. Sebab lain yang benign seperti vasovagal presyncope dan serangan panik. Sedangkan sebab yang serius, pada serebrovaskular biaanya disebabkan oleh TIA vertebrobasiler, kardiorespiratori biasanya disebabkan oleh aritmia jantung, dan pada kasus endokrin paling sering disebabkan oleh karena hipoglikemia. Aritmia harus tetap dipikirkan walaupun keluhan pasien hanya pusing berputar. Walaupun sangat jarang, pasien dengan perdarahan subaraknoid bisa datang dengan keluhan s-EVS. ${ }^{1}$

Beberapa studi menunjukan bahwa keluhan pusing, gangguang keseimbangan dan vertigo merupakan keluhan premonitori pada kasus verterbobasiler TIA. Keluhan ini mendahului beberapa hari sebelum stroke fosa posterior.

Ketika keluhan TIA pada gangguan pembuluh darah anterior inferior serebelar arteri yang memberikan cabang pada arteri labirintin, pasien akan mengeluhkan vertigo dengan gejala auditori berupa tuli sensorineural unilateral dan nistagmus tipe perifer yang disebabkan karena iskemia pada labirintin. Keluhan tersebut menyerupai keluhan pasien dengan Meniere. Keluhan pusing dan gangguan keseimbangan bisa juga disebabkan oleh karena diseksi arteri vertebralis, yang biasanya mengenai pasien yang berusia lebih muda yang disebabkan, karena cedera minor pada leher, olah raga angkat berat, postur kepala abnormal, manipulasi ciropraktik. ${ }^{1}$

\section{Acute Vestibular Syndrome}

AVS diartikan sebagai sebuah sindrom klinis dengan onset yang akut, vertigo kontinu, pusing atau gangguan keseimbangan yang bertahan dalam hitungan hari sampai minggu dan umumnya merupakan gejala yang baru, disertai dengan disfungsi sistem vestibular (muntah, nistagmus dan ketidak stabilan postur). Penting untuk mengetahui apaan pasien dengan gejala AVS mengalami perburukan kondisi (ekserbasi) bila melakukan pergerakan kepala. Keluhan eksaserbasi tersebuh harus dibedakan dengan pergerakan kepala yang memang betul menyebabkan pusing. Untuk membedakannya pasien dengan t-EVS tidak megalami keluhan sampai melakukan pergerakan kepala kesalah satu sisi yang terganggu. Sedangkan pada AVS pusing timbul baik pada istirahat dan memburuk dengan perubahan posisi kepala. ${ }^{1}$ Ada 10 pitfal dan pearls pada pasien dengan akut dizziness atau vertigo yang akan dijabarkan pada tabel 2

\section{Traumatic/Toxic AVS}

Pada pasien dengan t-AVS, sebab paling sering adalah trauma kepala atau toksikasi obat. Obat seperti antikonvulsan atau aminoglikosid. Kerancunan karbon monoksida juga harus dipikirkan. Kebanyakan pasien mengalami keluhan hanya 1 kali dengan serangan yang akut, dan membaik secara gradual dalam beberapa hari atau minggu ketika eksposur nya sudah tidak ada. Yang penting pada kasus serebrovaskular pada t-AVS pada pasien dengan keluhan yang tumpang tindih, seperti pasien dengan kerusakan pada labirintin karena trauma kepala atau intoksikasi alkohol dengan riwayat jatuh akan menutupi kelainan yang sebenarnya seperti diseksi arteri vertebralis yang menyebabkan infark serebelar.

Tabel 2. Sepuluh kesulitan dan pedoman dari keluhan vertigo dan dizziness

\begin{tabular}{lll}
\hline \multicolumn{1}{c}{ Kesulitan } & \multicolumn{1}{c}{ Pedoman } & \multicolumn{1}{c}{ Keterangan } \\
\hline $\begin{array}{l}\text { True Vertigo selalu melibatkan } \\
\text { gangguan telinga tengah }\end{array}$ & $\begin{array}{l}\text { Fokus pada waktu dan faktor } \\
\text { pencetus daripada tipe vertigo }\end{array}$ & $\begin{array}{l}\text { Gangguan serebrovaskular } \\
\text { seringkali dengan simptom true } \\
\text { vertigo.' }\end{array}$ \\
$\begin{array}{lll}\text { Gejala penyerta auditorik hanya } \\
\text { pada kasus perifer }\end{array}$ & $\begin{array}{l}\text { Hati hati kelaina auditorik pada } \\
\text { kasus vaskular }\end{array}$ & $\begin{array}{l}\text { Lateral pontine dan stroke pada } \\
\text { telinga dalam seringkali } \\
\text { menyebabkan tinitus dan hilang }\end{array}$ \\
& & pendengaran.
\end{tabular}

\section{Spontaneous AVS}

Pasien dengan s-AVS penting untuk dievaluasi pemeriksaan mata, karena bisa membedakan apakah ini lesi perifer atau lesi sentral. Kejadian paling sering pada s-AVS adalah neuritis vestibularis. Sekitar 10 sampai $20 \%$ pasien dengan s-AVS mengalami stroke (khususnya stroke pada batang otak maupun pada serebelum yang mengenai sekitar 95\% pasien dengan s- AVS). Sering kali serangan stroke muncul setelah serangan pusing yang berlangsung selama beberapa minggu sampai berapa bulan sebelumnya, yang menggambarkan gejala premonitori dari TIA. Sebab yang lain dari sAVS adalah defisiensi thiamin dan juga ensefalitis listeria. 
Pemeriksaan HINTS (head impulse, tipe nistagmus, skew deviation) ditambah keluhan hilang nya pendengaran yang dipemeriksa dengan gesekan tangan, dikatakan bisa menyingkirkan kemungkinan dari stroke lebih akurat bahkan dari MRI.

Pemeriksaan HINTS ini bisa dilakukan pada pasien dengan s-AVS dan s-EVS (bila pada pemeriksaan keluhan masih dirasakan). HINTS tidak bisa dipakai pada pasien dengan sindrom yang lain, khususnya tEVS karena pemeriksaan head impulse yang normal bias menyebabkan kesalahan mendiagnosa stroke pada pasien yang secara umum merupakan pasien dengan BPPV. Pasien dengan perdarahan serebelar sangat jarang datang hanya dengan keluhan dizziness atau tanpa defisit neurologi yang jelas (contoh disarteria) dan hanya sekitar $5 \%$ pasien dengan gangguan serebrovaskular datang dengan gambaran s-AVS merupakan perdarahan, sisanya merupakan stroke iskemik. Bila pasien dengan gambaran isolated dizziness tidak dianjurkan melakukan pemeriksaan dengan CT scan kepala tanpa kontras, hal ini dikarena CT Scan kepala sensitif untuk membedakan strok perdarahan dan strok sumbatan tetapi untuk mengevaluasi akut iskemia fosa posterior pada pasien dengan keluhan isolated dizziness. ${ }^{1}$

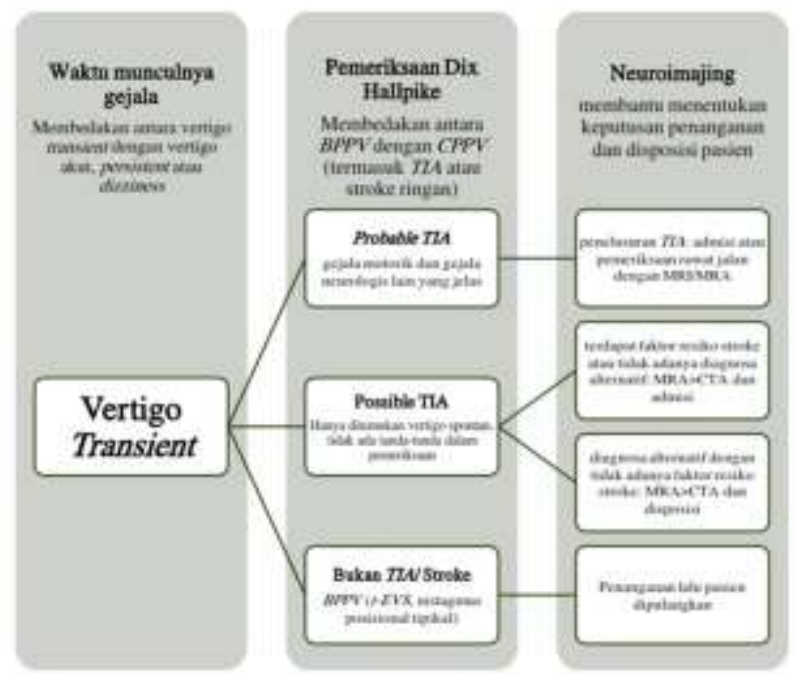

Gambar 3. Tutalaksana vertigo pada pasien dengan keluhan transien vertigo:

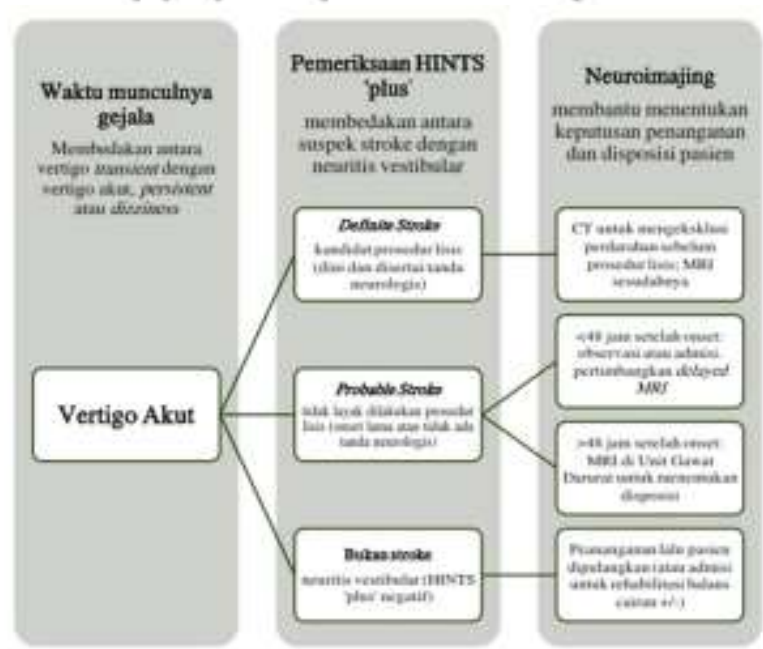

Gambar 4. Tatalaksana pada pasien dengan vertigo akut ${ }^{\prime}$ 


\section{Neuroimajing}

Secara ideal pasien dengan keluhan dizziness yang akut membutuhkan pencitraan. MRI lebih diutamakan dibandingkan dengan CT scan pada mayoritas kasus. Kecuali bila kita sangat memerlukan untuk mengeksklusi kemungkinan perdarahan sebelum tindakan trombolisis atau untuk mengetahui diseksi arteri vertebralis menggunakan CT angiografi. ${ }^{17}$ Waktu yang tepat untuk melakukan tindakan MRI juga sangat penting, karena resiko false negatif pada 48 jam pertama. Pada beberapa kasus penting untuk melakukan MRI ulangan bila hasil HINTS tes mencurigakan kearah proses sentral tetapi hasil MRI tidak menunjukan suatu yang signifikan. ${ }^{1}$

\section{Simpulan}

Secara umum pada kasus akut, berdasarkan waktu dan faktor pencetus memunculkan 4 kemungkinan sindrom pada pasien yang datang ke ruang emergensi dengan keluhan intermiten atau kontinu dizziness, yaitu triggered episodic vestibular syndrome (t-EVS), spontaneous EVS (sEVS), traumatik/toksik acute vestibular syndrome

\section{Daftar Rujukan}

1. Saber Tehrani AS, Kattah JC, Kerber KA, Gold DR, Zee DS, Urrutia VC and Newman- Toker DE. Diagnosing Stroke in Acute Dizziness and Vertigo: Pitfalls and Pearls. Stroke. 2018;49:788-795.

2.Thursiana $\mathrm{C}$ and Dewati E. Pedoman Tatalaksana Vertigo. 2017;1.

3.Aninditha.T. Buku Ajar Neurologi. 2017.

4. Ertl L, Morhard D, Deckert-Schmitz M, Linn J and Schulte-Altedorneburg G. Focal subarachnoid haemorrhage mimicking transient ischaemic attack--do we really need MRI in the acute stage? BMC Neurol.2014;14:80.

5. Lee H, Sohn Sl, Cho YW, Lee SR, Ahn BH, Park $B R$ and Baloh RW. Cerebellar infarction presenting isolated vertigo: frequency and vascular topographical patterns. Neurology.2006;67:1178-83.

6. Newman-Toker DE, Kerber KA, Hsieh YH, Pula $\mathrm{JH}$, Omron R, Saber Tehrani AS, Mantokoudis G, Hanley DF, Zee DS and Kattah JC. HINTS outperforms $A B C D 2$ to screen for stroke in acute continuous vertigo and dizziness. Acad Emerg Med.2013;20:986-96.

7.Ozono Y, Kitahara T, Fukushima M, Michiba T, Imai $\mathrm{R}$, Tomiyama $\mathrm{Y}$, Nishiike $\mathrm{S}$, Inohara $\mathrm{H}$ and Morita H. Differential diagnosis of vertigo and dizziness in the emergency department. Acta Otolaryngol. 2014;134:140-5.
(t-AVS), spontaneous AVS (s-AVS). Kebanyakan pasien TIA datang dengan keluhan s-EVS dan kebanyakan pasien dengan strok dan perdarahan datang dengan s-AVS (dengan beberapa pengecualian).

Untuk membedakan apakah suatu keluhan dizziness atau vertigo penting untuk dilakukan pemeriksaan HINTS PLUS (head impulse, tipe nistagmus, skew deviation) ditambah keluhan hilangnya pendengaran yang diperiksa dengan gesekan tangan, dikatakan bisa menyingkirkan kemungkinan dari strok lebih akurat bahkan dari MRI.

Secara ideal pasien dengan keluhan dizziness yang akut membutuhkan pencitraan. MRI lebih diutamakan dibandingkan dengan CT scan pada mayoritas kasus. Kecuali bila kita sangat memerlukan untuk mengeksklusi kemungkinan perdarahan sebelum tindakan trombolisis atau untuk mengetahui diseksi arteri vertebralis menggunakan CT angiografi. MRI DWI sensitif pada strok batang otak pada 72 jam sampai 100 jam paska infark.

8. Newman-Toker DE. Symptoms and signs of neuro-otologic disorders. Continuum (Minneap Minn). 2012;18:1016-40.

9. Kattah JC, Talkad AV, Wang DZ, Hsieh YH and Newman-Toker DE. HINTS to diagnose stroke in the acute vestibular syndrome: three- step bedside oculomotor examination more sensitive than early MRI diffusion-weighted imaging. Stroke. 2009;40:3504-10.

10.Martin-Schild S, Albright KC, Tanksley J, Pandav V, Jones EB, Grotta JC and Savitz SI. Zero on the NIHSS does not equal the absence of stroke. Ann Emerg Med. 2011;57:42-5.

11.Gottesman RF, Sharma P, Robinson KA, Arnan $M$, Tsui $M$, Ladha $K$ and Newman- Toker DE. Clinical characteristics of symptomatic vertebral artery dissection: a systematic review. Neurologist. 2012;18:245-54.

12.Newman-Toker DE, Moy E, Valente $E$, Coffey $R$ and Hines AL. Missed diagnosis of stroke in the emergency department: a crosssectional analysis of a large population-based sample. Diagnosis (Berl). 2014;1:155-166.

13.Kerber KA, Burke JF, Brown DL, Meurer WJ, Smith MA, Lisabeth LD, Morgenstern LB and Zahuranec DB. Does intracerebral haemorrhage mimic benign dizziness presentations? A population based study. Emerg Med J. 2012;29:43-6. 
14.Lawhn-Heath C, Buckle C, Christoforidis G and Straus C. Utility of head CT in the evaluation of vertigo/dizziness in the emergency department. Emerg Radiol.2013;20:45-9.

15.Newman-Toker DE, Della Santina CC and Blitz AM. Vertigo and hearing loss. Handb Clin Neurol. 2016;136:905-21.
16.Axer H, Grassel D, Bramer D, Fitzek S, Kaiser WA, Witte OW and Fitzek C. Time course of diffusion imaging in acute brainstem infarcts. J Magn Reson Imaging. 2007;26:905-12. 